\title{
MOBILIDADE DO SULFENTRAZONE NO PERFIL DE CLASSES DE SOLOS
}

\author{
Caio Vitagliano Santi Rossi ${ }^{1}$, Tiago Pereira Salgado ${ }^{2}$, Pedro Luís da Costa Aguiar \\ Alves $^{3}$ e José Marques Júnior ${ }^{4}$ \\ ${ }^{1}$ Pós-Graduando (Mestrado) em Proteção de Plantas. FCA/UNESP - Botucatu. Fazenda Experimental Lageado, \\ s/n. Departamento de Produção Vegetal Setor de Defesa Fitossanitária. Botucatu/SP. Caixa Postal - 237, CEP. \\ 18603-970. E-mail: cavsr@fca.unesp.br Tel.: (14) 68027205 ou 06. \\ ${ }^{2}$ Pós-Graduando (Mestrado) em Produção Vegetal, FCAV/UNESP - Jaboticabal \\ ${ }^{3}$ Professor Doutor. Departamento de Biologia Aplicada à Agropecuária, FCAV/UNESP - Jaboticabal. \\ ${ }^{4}$ Professor Doutor. Departamento de Solos e Adubos, FCAV/UNESP - Jaboticabal.
}

\section{RESUMO}

O trabalho objetivou determinar a mobilidade do sulfentrazone em duas classes de solos em função de índices pluviométricos crescentes, bem como possíveis influências das propriedades químicas e físicas de solos com diferentes teores de ferro na ação do herbicida. Foram utilizados como recipientes 36 tubos de PVC de $10 \mathrm{~cm}$ de diâmetro por $50 \mathrm{~cm}$ de comprimento. Os recipientes foram preenchidos com os solos e umedecidos a $65 \%(\mathrm{p} / \mathrm{p}) \mathrm{da}$ capacidade de saturação, quando fez-se a aplicação do sulfentrazone $(800 \mathrm{~g}$ i.a/ha) na área exposta dos solos. Na seqüência, foram simuladas chuvas diárias de $10 \mathrm{~mm}$ e, ao atingir-se o índice pluviométrico desejado (30, 60 e 90mm), foram desmontados seis tubos de cada solo (com e sem aplicação). Foram semeadas cinco sementes de sorgo (Sorghum bicolor) nas profundidades de 2,5-7,5-12,5-17,5-22,5-30,0 cm, que assim foram mantidas em casa de vegetação por 15 dias para avaliação da germinação e crescimento inicial. Decorrido esse tempo, foi realizada uma avaliação de possíveis alterações morfofisiológicas que pudesse ser caracterizada como efeitos tóxicos do produto e mediu-se o comprimento da parte aérea até a última lígula visível. As partes aéreas foram secas em estufa com circulação forçada de ar $\left(70^{\circ} \mathrm{C}\right.$ por $\left.96 \mathrm{~h}\right)$ para obtenção de matéria seca. Pelos resultados obtidos, verificou-se que no Latossolo Vermelho distroférrico o produto foi até os $12,5 \mathrm{~cm}$ com $90 \mathrm{~mm}$ de precipitação e no Latossolo Vermelho - Amarelo o sulfentrazone foi pouco móvel, permanecendo nos $7,5 \mathrm{~cm}$ superficiais, independentemente da precipitação.

PALAVRAS-CHAVE: Herbicida, lixiviação, adsorção, óxido de ferro.

\section{SULFENTRAZONE MOBILITY IN THE PROFILE OF CLASSES OF SOILS ABSTRACT}

The objective of this study was to determine the mobility of sulfentrazone in two soils classes as a function of increasing rain indices, as well as possible influences of the chemical and physical properties of soils with different iron oxides contents, on the herbicide action. The containers were $36 \mathrm{PVC}$ tubes $(10 \mathrm{~cm}$ diameter X $50 \mathrm{~cm}$ long). The containers were filled with soils and irrigated in $65 \%(\mathrm{w} / \mathrm{w})$ and, then, the application of sulfentrazone $(800 \mathrm{~g} \mathrm{a} . \mathrm{i} / \mathrm{ha})$ was done on the exposed area. Subsequently, daily rainfalls of $10 \mathrm{~mm}$ were simulated and, as the desired rain indices were reached $(30,60$ and 90mm), six PVC tubes from each soil (with and without application) were disassembled. Five sorghum (Sorghum bicolor) seeds were sowing on soil from the depths 2,5-7,5-12,5-17,5-22,5-30,0 cm, and were maintained in a greenhouse for 15 days to evaluation of the germination and initial growth. After this time, an evaluation of possible morphophysiological changes that could be characterized as toxic effects of the product was done and the length of the shoot up to the last visible ligule. After measurement the shoots were dried in a forced draught over $\left(70^{\circ} \mathrm{C}\right.$ for $\left.96 \mathrm{~h}\right)$ to determine the dry matter. The results indicated that on the Dusky Red Latosol (Typic Acrustox) the product was percolated down to $12,5 \mathrm{~cm}$ with $90 \mathrm{~mm}$ rainfall and on the Yellowish Red Latosol (Typic Acrustox) the sulfentrazone had little mobility, staying on the top $7,5 \mathrm{~cm}$, independently the rainfall. 
KEY WORDS: Herbicide, iron oxides, leaching, adsorption.

\section{INTRODUÇÃO}

No solo, o herbicida pode sofrer adsorção, lixiviação e/ou degradação por processos físicos, químicos e biológicos, além de ser absorvido pelas plantas daninhas e/ou cultivadas (Resende et al., 1995). Esses processos são dependentes do tipo de solo e das condições climáticas (Brady, 1974). É de fundamental importância conhecer tais processos para a previsão do comportamento de um herbicida nas diferentes classes de solo, para a seleção de dosagens adequadas e para evitar efeitos prejudiciais dos herbicidas sobre o ambiente e as culturas subseqüentes (Velini,1992). Paula Neto (1999) apresentou a hipótese de que os óxidos de ferro, por suas características de carga variável (dependentes do $\mathrm{pH}$ do solo), superfície específica elevada e com teores diferenciados na fração argila nos solos da região de Ribeirão Preto, juntamente com suas associações com a matéria orgânica, possam estar influenciando no comportamento do sulfentrazone no controle da tiririca (Cyperus rotundus).

Para os herbicidas de elevada capacidade adsortiva, o conteúdo de matéria orgânica é geralmente o fator mais importante, pois, quanto mais alto menor a lixiviação (Sprankle et al., 1975; Mandhun et al., 1986; Senesi et al., 1994). A lixiviação será ainda maior em solos de textura arenosa que em solos siltosos ou argilosos (Nicholls, 1988).

Além dos fatores cobertura e densidade do solo, o $\mathrm{pH}$, ferro total, matéria orgânica e cristalinidade dos óxidos de ferro, também podem reduzir a eficiência dos herbicidas, influenciando nas perdas por lixiviação, na contaminação das águas subterrâneas (O'Connor \& Wierenga, 1973), na relação planta-herbicida-ambiente, e ainda na persistência e decomposição dos resíduos de herbicidas no solo (Matallo, 1999).

Alguns trabalhos demostraram que as argilas não contribuem significativamente no processo de adsorção de herbicidas ácidos pelos solos. Entretanto, a caulinita e os óxidos e hidróxidos de ferro e alumínio contribuem para a adsorção, uma vez que a carga superficial destes minerais de argila é dependente do $\mathrm{pH}$, e a adsorção é resultado da lixiviação iônica entre minerais e o ânion de herbicida em níveis relativamente baixos de pH (Green, 1974; Loux et al., 1989).

A lixiviação apresenta como determinantes primárias de sua intensidade, a precipitação acumulada no período considerado, a capacidade de transporte pela água e a intensidade com que o produto é adsorvido ao solo. Este processo apresenta dois aspectos importantes: é fundamental para a incorporação superficial da maioria dos herbicidas, permitindo que estes possam atingir as sementes ou plantas em germinação e, quando excessiva, a lixiviação pode carrear o produto para camadas do solo mais profundas, limitando a ação do mesmo e podendo, inclusive, promover a contaminação do lençol freático (Velini, 1992).

Os Latossolos constituem o mais expressivo agrupamento de solos da quadrícula de Ribeirão Preto, SP, segundo levantamento semidetalhado feito por Oliveira \& Prado (1987), representando $77 \%$ da área da quadrícula. Estes solos são altamente intemperizados, com baixa relação silte/argila $(0,6)$ para alguns Latossolos com textura argilosa ou muito argilosa e, conseqüentemente, grande superfície específica, característica essa relacionada aos fenômenos físico-químicos de superfície (Resende et al., 1995).

O sulfentrazone, ( $\mathrm{N}$ - [2,4-dicloro-5- [4-(difluorometil)-4,5- dihidro-3 metil -5-oxo- $1 \mathrm{H}$ 1,2,4-triazol -1-il] metanosulfonamida), do grupo químico aril triazolinonas, é um herbicida recentemente desenvolvido para aplicação preferencialmente em pré-emergência, controlando várias espécies de plantas daninhas infestantes, dico e monocotiledôneas, das culturas da cana-de-açúcar e soja, além do seu uso em pátios industriais (Rodrigues \& Almeida, 1998).

Neste contexto, o conhecimento da relação sulfentrazone - solo é muito importante, visto que existem mecanismos, tais como adsorção e lixiviação, que interferem na ação deste quando aplicado na pré-emergência das plantas daninhas e os problemas ambientais que poderiam acarretar. 
Em virtude do relatado, o presente trabalho teve como objetivo observar a percolação do sulfentrazone em várias classes de solo em função de índices pluviométricos crescentes, bem como possíveis influências das propriedades químicas e físicas de solos com diferentes teores de ferro na ação do sulfentrazone.

\section{MATERIAL E MÉTODOS}

O presente trabalho foi instalado e conduzido em casa-de-vegetação, pertencente ao Departamento de Biologia Aplicada à Agropecuária, da Faculdade de Ciências Agrárias e Veterinárias - UNESP - Campus de Jaboticabal, SP. Como substrato foram utilizados materiais de solos coletados na camada arável de um Latossolo Vermelho - Amarelo (LVA), situado no município de São Carlos, SP e de um Latossolo Vermelho distroférrico (LVdf), considerado um dos latossolos mais velhos do Brasil, situado no município de Luiz Antônio, SP. Esses solos foram coletados em área cujo histórico não constava qualquer aplicação de herbicidas.

Após a coleta, foram postos para secar à sombra por um período de $48 \mathrm{~h}$, quando, então, foram peneirados. Foram retiradas amostras para serem submetidas às análises química e granulométrica no Departamento de Solos e Adubos da FCAVJ (Tabelas 1 e 2).

A análise granulométrica da terra fina foi realizada pelo método da pipeta, utilizando solução de $\mathrm{NaOH} 0,1 \mathrm{~N}$ como dispersante químico e agitação com aparato de baixa rotação (EMBRAPA, 1979).

$\mathrm{O} \mathrm{pH}$ foi determinado potenciometricamente utilizando relação 1:2,5 de solo: $\mathrm{CaCl}_{2} \quad 0,01$ mol.L ${ }^{-1}$.

O cálcio, magnésio e potássio trocáveis, e o fósforo disponível foram extraídos utilizandose o método da resina trocadora de íons (Raij \& Quaggio, 1983) e a matéria orgânica segundo a metodologia da EMBRAPA (1979). Os óxidos de ferro do ataque sulfúrico $\left(\mathrm{Fe}_{2} \mathrm{O}_{3}\right)$ foi determinado após digestão com $\mathrm{H}_{2} \mathrm{SO}_{4}$ 1:1 segundo o método descrito por Vettori (1969), modificado por EMBRAPA (1979).

Foi feita a determinação da densidade e da capacidade de saturação desses solos pelo método gravimétrico (EMBRAPA, 1979), para permitir o preenchimento uniforme dos tubos de PVC (recipientes) com os materiais de solos, simulando sua densidade natural. Antes da aplicação do herbicida, os materiais de solos foram umedecidos até $65 \%$ de sua capacidade de saturação.

Como recipientes foram utilizados 36 tubos de PVC de $10 \mathrm{~cm}$ de diâmetro por $50 \mathrm{~cm}$ de comprimento. Estes tubos foram seccionados na metade de cima para baixo e foram fixados com fita adesiva, reconstituindo o original. As bases dos tubos foram fechadas por meio de uma tela tipo mosquiteiro e, em seguida, estes foram parcialmente enterrados em areia, que serviu de suporte. Desta maneira, foram montados dois conjuntos: um para testemunha e outro para aplicação do sulfentrazone.

Após a montagem dos conjuntos com os tubos preenchidos com os solos, foi realizada a aplicação do sulfentrazone ( $800 \mathrm{~g}$ i.a./ha) na área exposta dos solos contidos nos tubos de PVC. Os dados das condições climáticas ao término das aplicações encontram-se na Tabela 3. A aplicação do produto foi realizada com pulverizador costal mantido a pressão constante (ar comprimido), munido de barra com 4 bicos XR 11002 e regulado para uma vazão de 2001/ha.

Após a aplicação, foram simuladas chuvas diárias de $10 \mathrm{~mm}$ e, a medida que se atingia o índice pluviométrico desejado (30,60 ou 90mm), foram desmontados três tubos de cada solo, separando-se as partes e deitando-os. No solo contido em cada metade de tubo foram postas para germinar cinco sementes de sorgo (Sorghum bicolor) a 2,5; 7,5; 12,5; 17,5; 22,5 e $30,0 \mathrm{~cm}$ da superfície na qual foi aplicado o produto. O ensaio de germinação e crescimento inicial foi conduzido por 15 dias em condições de casa-de-vegetação.

O delineamento experimental utilizado para cada classe de solo foi o de blocos casualizados (DBC) com seis tratamentos constituindo as parcelas e a interação entre os 
fatores principais (três índices pluviométricos com ou sem herbicida) e as seis profundidades de semeadura as sub parcelas em 3 repetições para cada classe de solo. Cada parcela experimental constou de um tubo de $50 \mathrm{~cm}$, composto por 2 metades.

Aos 15 dias após a semeadura foi realizada uma avaliação visual de possíveis alterações morfofisiológicas nas plântulas de sorgo que pudessem ser caracterizadas como efeitos tóxicos do produto. Esta avaliação baseou-se em critérios qualitativos segundo a escala de notas da EWRC (1964) e feita para cada linha de semeadura, que representou uma profundidade da aplicação. Na seqüência, foram realizadas medições do comprimento da parte aérea das plântulas, as quais foram posteriormente cortadas e postas para secar em estufa com circulação forçada de ar $\left(70^{\circ} \mathrm{C}\right.$ por 96 horas) para obtenção da biomassa seca. A partir do número de plântulas medidas pôde-se atribuir a porcentagem de sobrevivência para cada linha de semeadura.

Os dados obtidos foram submetidos a análise de variância pelo teste $\mathrm{F}$ e as médias foram comparadas pelo teste de Tukey ao nível de 5\% de probabilidade. Os dados de biomassa seca e altura do sorgo não sofreram transformação. Os dados de porcentagem obtidos foram transformados para arc seno $\sqrt{(x+1) / 100}$.

\section{RESULTADOS E DISCUSSÃO}

Nas testemunhas referentes às classes de solo, a intoxicação nas plântulas de sorgo foi nula, ou seja, a nota foi 1 para todas.

\section{Latossolo Vermelho distroférrico (LVdf)}

Para a chuva simulada de $30 \mathrm{~mm}$, observou-se que o sulfentrazone provocou injúrias muito severas (nota 8, Tabela 4) nas plântulas de sorgo provenientes de sementes que foram postas para germinar nos $2,5 \mathrm{~cm}$ superficiais, com necrose e encarquilhamento das folhas, algumas amarelecidas ou totalmente mortas. Nos 7,5 e $12,5 \mathrm{~cm}$ de profundidade, a intoxicação foi regular (nota 4) e leve (nota 3), respectivamente, com leve amarelecimento, além de redução na altura das plântulas. Dos 17,5 aos $30,0 \mathrm{~cm}$ a fitotoxicidade do produto foi nula (nota 1)

Na precipitação simulada de $60 \mathrm{~mm}$, o sulfentrazone proporcionou forte injúrias (nota 7) e média (nota 5) nos 2,5 e 7,5 cm de profundidade respectivamente, causando o amarelecimento e encarquilhamento das folhas. Nos 12,5 e $17,5 \mathrm{~cm}$ de profundidade, os sintomas de intoxicação foram leve (nota 3 ) e muito leve (nota 2), respectivamente, com diminuição na altura das plantas.

Com a chuva de $90 \mathrm{~mm}$, observou-se que os danos causados pelo sulfentrazone se concentram nos 2,$5 ; 7,5 ; 12,5 \mathrm{~cm}$ de profundidade e se manifestam com maior intensidade, sendo que os sintomas nas plântulas foram muito forte (nota 8), forte (nota 7) e quase forte (nota 6) respectivamente, com encarquilhamento e amarelecimento das folhas, com redução na altura dessas. Dos 17,5 até os $30 \mathrm{~cm}$ de profundidade, o sintoma foi de leve (nota 3 ) a muito leve (nota 2), com leve amarelecimento e diminuição da altura das plântulas.

Com base nesses resultados visuais de toxicidade do sulfentrazone nas plântulas nas diferentes profundidades, observou-se uma tendência do arraste e acúmulo do sulfentrazone no perfil do solo, de acordo com os índices pluviométricos impostos.

$\mathrm{Na}$ Tabela 5 pode-se observar que os efeitos isolados do sulfentrazone, independentemente da profundidade, sobre a altura, sobrevivência e biomassa seca das plantas de sorgo não diferiu da testemunha em nenhuma das precipitações. Quando se analisa o efeito da profundidade, independentemente dos efeitos da aplicação ou não do herbicida e das precipitações, verificou-se que as plantas próximas à superfície $(2,5 \mathrm{~cm}$ de profundidade $)$ mostram-se menores, com menor biomassa e com menor sobrevivência quando comparadas às plantas das demais profundidades. Esse resultado deve-se, provavelmente, ao fato dessas plantas estarem mais sujeitas à deficiência hídrica. Para a altura e biomassa, observou-se 
aumento gradual em função da profundidade, apresentando uma estabilização a partir dos 17,5 cm. Para a sobrevivência, esta estabilização ocorreu já a partir dos 7,5 cm.

Ainda na Tabela 5 pode-se observar que o efeito da interação entre os fatores principais foi significativa para as três características analisadas nas plantas de sorgo. As plantas de sorgo que se encontravam de 2,5 até $7,5 \mathrm{~cm}$ de profundidade no solo tratado com sulfentrazone eram menores que as das demais profundidades nas três precipitações. Na testemunha sem aplicação este efeito só foi observado até os $2,5 \mathrm{~cm}$. Ao se analisar o efeito na linha de semeadura, observou-se que as plantas que se encontravam de 2,5 até 7,5 cm de profundidade no solo tratado com sulfentrazone e submetido a uma chuva de $30 \mathrm{~mm}$ eram menores que as do solo testemunha e submetido a uma chuva de até $60 \mathrm{~mm}$. Nas demais profundidades não se constatou diferença na altura das plantas entre o solo tratado ou não, sob as diferentes precipitações.

Para todas as características avaliadas ocorreu interação significativa entre os fatores principais.

Pode-se observar na Tabela 6 que a altura do sorgo nos 30, 60 e $90 \mathrm{~mm}$ de precipitação o efeito do sulfentrazone diferiu significativamente até 0 s $7,5 \mathrm{~cm}$ de profundidade, a partir dessa profundidade não houve diferença significativa. Se comparado com a testemunha nos 30,60 e $90 \mathrm{~mm}$ de precipitação a diferença do sulfentrazone foi significativa até os $7,5 \mathrm{~cm}$ de profundidade.

Pode-se observar, na Tabela 7, que a sobrevivência do sorgo no solo tratado com sulfentrazone e sob 30 e $90 \mathrm{~mm}$ de precipitação foi menor nos $2,5 \mathrm{~cm}$ superficiais, a partir dessa profundidade não houve diferença significativa; no caso da precipitação de $60 \mathrm{~mm}$ não houve diferença significativa. No solo testemunha, esse efeito só foi observado quando o solo foi submetido a $30 \mathrm{~mm}$ de chuva. Dentro de cada profundidade, verificou-se apenas efeito nos $2,5 \mathrm{~cm}$, onde as plantas do solo tratado e submetido a $30 \mathrm{~mm}$ mostraram-se menores que as demais.

Pode-se observar na Tabela 8, que a biomassa da parte aérea das plantas de sorgo desenvolvidas até $12,5 \mathrm{~cm}$ no solo tratado com sulfentrazone foi inferior ao das plantas nas demais profundidades, sob três índices pluviométricos, sendo que a partir dessa profundidade não houve diferença significativa. Se comparado com a testemunha, as precipitações de 30, 60 e $90 \mathrm{~mm}$ com sulfentrazone não tiveram diferença significativa.

$\mathrm{Na}$ testemunha o mesmo efeito foi observado no solo submetido a simulação de chuva de $30 \mathrm{~mm}$. Com o aumento do índice pluviométrico simulado, houve redução no efeito, sendo que sob $90 \mathrm{~mm}$ praticamente não houve mais efeito. Ao se analisar o efeito na linha de semeadura, verificou-se que as plantas que se encontram de 2,5 a 7,5 cm de profundidade no solo tratado com sulfentrazone e submetido a precipitação de $30 \mathrm{~mm}$ possuíam menor biomassa que as plantas das demais profundidades.

\section{Latossolo Vermelho - Escuro (LVA)}

Com a simulação da chuva de $30 \mathrm{~mm}$, observou-se que o sulfentrazone causou sintomas quase forte (nota 6, Tabela 4), médio (nota 5) e regular (nota 4) de intoxicação nas plântulas que se encontravam nas distâncias de 2,5; 7,5 e 12,5 cm, respectivamente, causando o encarquilhamento e amarelecimento das folhas, também redução na altura destas. Já dos 17,5 aos 30,0 cm de profundidade, o sintoma de intoxicação pelo produto foi leve (nota 3), com diminuição da altura.

Com a simulação da chuva de $60 \mathrm{~mm}$, observou-se que o sulfentrazone provocou os sintomas quase forte (nota 6) e médio (nota 5) de intoxicação nas plântulas que se encontravam nas profundidades de 2,5 e $7,5 \mathrm{~cm}$ respectivamente, e regular (nota 4) nas profundidades de 12,5 e $17,5 \mathrm{~cm}$, causando o encarquilhamento e amarelecimento das folhas e também a diminuição na altura destas. Já dos 22,5 aos $30,0 \mathrm{~cm}$ de profundidade houve um sintoma leve (nota 3) de intoxicação pelo produto, com diminuição da altura das plântulas. 
Com a simulação da chuva de $90 \mathrm{~mm}$, observou-se que o sulfentrazone provocou sintomas quase forte (nota 6) nas plântulas que se encontravam nas profundidades de 2,5 e 7,5 cm; médio (nota 5) nos 12,5 cm e regular (nota 4) nos 17,5 e 22,5 cm de profundidade, causando o encarquilhamento e amarelecimento das folhas e a diminuição da altura destas. Já nos $30,0 \mathrm{~cm}$ de profundidade as plântulas apresentaram um sintoma leve (nota 3) de intoxicação, com diminuição da altura.

Com base nos resultados visuais de toxicidade do sulfentrazone às plântulas que se encontravam nas diferentes profundidades, verificou-se um arraste por igual do sulfentrazone no perfil deste solo a medida que os índices pluviométricos impostos aumentavam.

$\mathrm{Na}$ Tabela 9 pode-se observar que, independentemente da profundidade de semeadura, as plantas que se desenvolveram no solo tratado com sulfentrazone e exposto a $90 \mathrm{~mm}$ de chuva apresentavam-se menores que as da testemunha exposta a $60 \mathrm{~mm}$, com mesmo efeito ocorrendo quando se analisou a biomassa seca, com o adicional de que as plantas da testemunha sob $30 \mathrm{~mm}$ de chuva também apresentaram menos biomassa seca que as da testemunha sob $60 \mathrm{~mm}$. Quanto à sobrevivência, verificou-se que esta foi menor nas plantas da testemunha submetida a $30 \mathrm{~mm}$ quando comparadas às da testemunha submetida a $60 \mathrm{~mm}$.

Com relação ao efeito isolado da profundidade, independentemente se o solo recebeu ou não sulfentrazone e do índice pluviométrico simulado, verificou-se que as plantas que se encontravam até $7,5 \mathrm{~cm}$ eram menores e com menos biomassa que as das demais profundidades, sendo que as plantas que se encontravam aos 12,5 cm apresentaram um comportamento intermediário. Quanto a sobrevivência, verificou-se apenas que essa foi maior nas plantas oriundas da semeadura aos $7,5 \mathrm{~cm}$ quando comparada às de $2,5 \mathrm{~cm}$.

Nesta classe de solo não foi verificada interação significativa do efeito dos fatores principais sobre as três características analisadas.

Segundo Upchurch (1966), algumas propriedades dos solos como $\mathrm{pH}$, teor de argila, ferro total, matéria orgânica e cristalinidade dos óxidos de ferro podem reduzir a eficiência dos herbicidas, influenciando nas perdas por lixiviação. Paula Neto (1999), estudando a influência de atributos de diferentes classes de solos (LVA, LV, LVdf e NV) na eficiência do sulfentrazone no controle da tiririca (Cyperus rotundus), observou que a eficiência do herbicida diminuiu com o aumento no teor de óxidos de ferro e que os teores de argila e de matéria orgânica não afetaram a eficiência do produto, sendo o LVdf e NV os solos mais limitantes ao uso desse herbicida.

Um dos fatores que influenciou a ação do herbicida foi a saturação do solo, visto que quanto maior foi o índice pluviométrico maior foi a intensidade de injúria nas plantas, principalmente quando se comparou os efeitos de $90 \mathrm{~mm}$ de precipitação com os de 30 e 60 $\mathrm{mm}$. Alves et al. (1999) verificaram que num LV o sulfentrazone proporcionou excelente controle da tiririca independentemente da umidade, enquanto num NV o herbicida somente controlou a planta daninha quando a umidade do substrato era ou foi elevada para $90 \%(\mathrm{p} / \mathrm{p})$.

Observou-se que com o aumento da saturação do solo, houve um aumento na percolação do produto no perfil dos dois solos, nos quais se observou atividade do herbicida ao longo do perfil.

Oppong \& Sagar (1992) estudando o movimento do triasulfuron em um perfil de solo, através de bioensaio, observaram que o conteúdo de matéria orgânica no solo e a quantidade e frequiência de chuva tiveram relação inversa, os quais influenciaram diretamente na lixiviação do produto. Pool \& Du-Toit (1995), estudando a lixiviação dos herbicidas imazamethabenz metil e chlorsulfuron + metsulfuron metil em estufa em oito diferentes tipos de solos, observaram que os herbicidas lixiviaram somente $60 \mathrm{~mm}$ em um solo de baixo $\mathrm{pH}$ e mais de $240 \mathrm{~mm}$ em um solo alto $\mathrm{pH}$. A lixiviação de ambos herbicidas foi influenciada pelo $\mathrm{pH}$ do solo e, possivelmente, pelo tipo do mineral de argila.

O solo LVdf, que tinha $\mathrm{pH}$ de 4,6 e teor de óxido ferro de $30,26 \%$, apresentou ação do herbicida concentrada na camada superficial do solo, provavelmente em decorrência dos elevado teor do óxido. Paes et al. (1999) observaram, em condições de casa-de-vegetação, a 
mobilidade do dimethenamid em solos com textura franco-argilo-arenosa, argilosa, areiafranca e arenosa, com simulação de precipitação de chuva de 45 e $90 \mathrm{~mm}$, que o dimethenamid no solo arenoso foi fortemente arrastado, no com textura areia-franca, com 45 mm de chuva permaneceu aos 10 a $15 \mathrm{~cm}$ de profundidade, com $90 \mathrm{~mm}$ permaneceu dos 20 a $30 \mathrm{~cm}$, já no argiloso e no franco-argilo-arenoso o comportamento foi similar, permanecendo nos $5 \mathrm{~cm}$ superficiais da coluna.

No LVA ocorreu uma situação similar à anterior, porém com uma melhor distribuição do produto ao longo do perfil do solo, mesmo com este apresentando um elevado teor de matéria orgânica $\left(55 \mathrm{~g} / \mathrm{dm}^{3}\right)$, demonstrando assim que não foi a quantidade de matéria orgânica que interferiu na ação do sulfentrazone e sim o teor de ferro. Oliveira et al. (1999) observou em condições de casa-de-vegetação que aplicando flumioxazin e metribuzin em um solo Podzólico Vermelho - Amarelo câmbico (PVC) e um Latossolo Vermelho - Amarelo textura média (LVm), com simulação de precipitação de chuva de 45 e $90 \mathrm{~mm}$, que o flumioxazin no PVC não ultrapassou $5 \mathrm{~cm}$ superficiais, já o $\mathrm{LVm}$ atingiu $10 \mathrm{~cm}$ superficiais na coluna e o metribuzin com maior mobilidade em ambos os solos e condições, chegando aos $20 \mathrm{~cm}$ no PVC úmido e $45 \mathrm{~cm}$ no LVm seco.

\section{CONCLUSÕES}

A mobilidade do sulfentrazone tem comportamento diferenciado entre as classes de solos estudados, sendo pouco móvel no LVdf e mais móvel no LVA.

A eficiência do sulfentrazone aumenta com o teor de umidade do solo. E uma precipitação simulada de $90 \mathrm{~mm}$ ativa o produto, mesmo nos solos onde é baixa a mobilidade do sulfentrazone.

A distribuição do produto diminui com o aumento do teor de óxido de ferro no solo LVdf, com $30,26 \%$, o que ocorreu inversamente no LVA, com 12,24\%.

Aparentemente, as variações nos teores de argila e de matéria orgânica dos solos não interferem diretamente na efíciência do sulfentrazone. 


\section{LITERATURA CITADA}

ALVES, P.L.C.A.; SOUZA, C.J.; KUVA, M.A.; MATTOS, E.D.; BORGES, A.; MARQUES Jr., J. Efeitos do teor de umidade do solo sobre a eficiência do herbicida sulfentrazone no controle da tiririca (Cyperus rotundus L.). In: CONGRESO ALAM, 14., CONGRESO ANUAL COMALFI, 29. Cartagena ,1999, Resumenes..., Cartagena: COMALFI. p.74.

BRADY, N. C. The nature and properties of solis. 8. ed., New York: Macmillan, 1974. 639p.

EMPRESA BRASILEIRA DE PESQUISA AGROPECUÁRIA. Serviço Nacional de Levantamento e Conservação de Solos. Manual de métodos de solo. Rio de Janeiro, 1979.

EMPRESA BRASILEIRA DE PESQUISA AGROPECUÁRIA. Serviço Nacional de Levantamento e Conservação de Solos. Manual de métodos de solo. Rio de Janeiro, 1979.

EUROPEAN WEED RESEARCH COUNCIL. Cittee of methods in Weed Research. Weed Research, v.4, p.88, 1964.

GREEN, R.E. Pesticide-clay-water interactions. In: GUELZI, W. D. (Ed.) Pesticides in soil and water. Madinson: SSSA, 1974. p. 3-37.

LOUX, M. M.; LIBEBL, R. A.; SLIFE, F. W. Adsorption of imazaquin and imazethapyr on soils, sediments, and selected adsorbents. Weed Science, v.37, p. 712-718, 1989.

MANDHUN, Y. A.; YOUNG, J. L.; FREED, V. H. Binding of herbicides by water-soluble organic materials from soil. Journal Environmental Quality, v.15, n.1, p.64-68,1986.

MATALLO, M. B. La reación suelo- herbicida: decomposion, resíduo y contaminaçion, manejo. In: CONGRESO LATINO AMERICANO, 14., 1999, Cartagena. Resumenes...

NICHOLLS, P. H. Factors influencing entry of pesticides into soil water. Pesticide Science, n.22, p.123-137, 1988.

O'CONNOR, G. A.; WIERENGA, P. J. The persistence of 2,4,5- T in greenhouse lysimeter studies. Soil Science Society of America Proceedings, v.37, p. 398-400, 1973.

OLIVEIRA, J. B.; PRADO, H. Levantamento pedológico semidetalhado do Estado de São Paulo: quadrícula de São Carlos. Campinas: Instituto Agronômico, 1987. 188p. (Boletim Científico, 98).

OLIVEIRA, M. F. de; SILVA, A. A. da; FERREIRA, F. A., RUIZ, H. A. Lixiviação de flumioxazin e metribuzin em dois solos em condições de laboratório. Planta Daninha, v. 17, n. 2, p.207-215, 1999.

OPPONG, F. K.; SAGAR, G.R. The activity and mobility of triasulfuron in soil as influenced by organic matter, duration, amount and frequency of rain. Weed Research, v.32, n.3, p.157165, 1992. 
PAES, J. M. V.; ARAÚJO, S. S.; SIlVA, A. A. da; RUIZ, H. A.; OlIVEIRA, M. F. de. Mobilidade do dimethenamid em diferentes solos. Planta Daninha, v. 17, n. 1, p.31-39, 1999.

PAULA NETO, J. F. Influência de atributos de solos na eficiência do sulfentrazone no controle de tiririca (Cyperus rotundus L.). 1999. 80f. Monografia (Trabalho de graduação em Agronomia) - Faculdade de Ciências Agrárias e Veterinárias, Universidade Estadual Paulista, Jaboticabal,1999.

POOL, C. F.; DU-TOIT, D. Leaching depth of imazamethabenz methyl and chlorsulfuron + metsulfuron methyl in different soils. Applied Plant Science, v.9, n.2, p.43-47,1995.

RAIJ, B. van, QUAGGIO, J. A. Métodos de análise de solo para fins de fertilidade. Campinas: Instituto Agronômico, 1983. (Boletim Técnico, 81).

RESENDE, M.; CURI, N.; REZENDE, S. B.; CORRÊA, G. F. Pedologia: base para distinção de ambientes. Viçosa: NEPUT, 1995. p.304.

RODRIGUES, B. N.; ALMEIDA, F. S. Guia de herbicidas. 4. ed. Londrina: edição dos autores, 1998. p. 518-521.

SENESI, N.; BRUNETTI, G.; LA CAVA, P. Adsorption of alachlor by humic acids from sewage and amended and non-amended soils. Soil Science, v.157, n.3, p.176-184, 1994.

SPRANKLE, P.; MEGGITT, W. F.; PENNER, D. Adsorption, mobility, and microbial degradation of glyphosate in the soil. Weed Science, v.23, n.3, p.229-234, 1975.

UPCHURCH, R. P. Behavior of herbicides in soil. Res. Rev., v.16, p.45-85, 1966.

VELINI, E. D. Comportamento de herbicidas no solo. In: SIMPÓSIO NACIONAL SOBRE MANEJO DE PLANTAS DANINHAS EM HORTALIÇAS, 1992, Botucatu. Resumos... p.44-64.

VETTORI, L. Métodos de análise de solo. Rio de Janeiro, EMBRAPA/SNLCS, 1969. 34p. (Boletim Técnico, 7). 
Tabela 1. Resultados da análise* química e de óxido de ferro de uma amostra das classes dos solos utilizados como substratos. Jaboticabal, 1999/2000.

\begin{tabular}{|c|c|c|c|c|c|c|c|c|c|c|c|}
\hline \multirow[t]{2}{*}{ Solo } & \multirow{2}{*}{$\begin{array}{c}\mathbf{p H} \\
\mathrm{CaCl}_{2}\end{array}$} & \multirow{2}{*}{$\begin{array}{l}\text { M.O. } \\
\text { g/dm }\end{array}$} & \multirow{2}{*}{$\begin{array}{l}\text { P res. } \\
\text { mg/dm }\end{array}$} & $\mathbf{K}$ & $\mathbf{C a}$ & Mg & $\mathbf{H}+\mathbf{A l}$ & SB & $\mathbf{T}$ & \multirow{2}{*}{$\begin{array}{c}\mathrm{V} \\
(\%)\end{array}$} & \multirow{2}{*}{$\begin{array}{c}\mathrm{Fe}_{2} \mathrm{O}_{3} \\
(\%)\end{array}$} \\
\hline & & & & \multicolumn{6}{|c|}{ mmolc/dm } & & \\
\hline LVA & 4,0 & 55 & 2 & 1,6 & 6 & 2 & 121 & 9,6 & 130,6 & 7 & 12,24 \\
\hline LVdf & 4,6 & 31 & 4 & 1,1 & 14 & 6 & 52 & 21,1 & 73,1 & 29 & 30,26 \\
\hline
\end{tabular}

Tabela 2. Resultados da análise* granulométrica de uma amostra dos solos utilizados como substratos. Jaboticabal, 1999/2000.

\begin{tabular}{lccccc}
\hline Classes & \multicolumn{5}{c}{ Granulometria (\%) } \\
\cline { 2 - 6 } de solo & Argila & Limo & Areia Fina & Areia Grossa & Classe Textural \\
\hline LVA & 61 & 14 & 10 & 15 & Argilosa \\
LVdf & 55 & 33 & 8 & 4 & Argilosa \\
\hline Realizada pelo Depto de Solos e Adubos - FCAVJ/UNESP.
\end{tabular}

Tabela 3. Condições climáticas ao término das aplicações. Jaboticabal, 1999/2000.

\begin{tabular}{cccccccc}
\hline \multirow{2}{*}{$\begin{array}{c}\text { Classes } \\
\text { de solo }\end{array}$} & \multirow{2}{*}{ Início } & \multirow{2}{*}{ Final } & \multicolumn{2}{c}{ Temp $^{\mathbf{}} \mathbf{C}$} & \multirow{2}{*}{$\begin{array}{c}\text { UR } \\
\text { (\%) }\end{array}$} & $\begin{array}{c}\text { Vento } \\
\text { Km/h }\end{array}$ & Nuvens \\
\cline { 4 - 5 } & & & $\mathbf{A R}$ & Solo & & & \\
\hline LVA & $16: 56$ & $17: 04$ & 29 & 33,3 & 54 & 0 & $6 / 8$ \\
LVdf & $16: 56$ & $17: 04$ & 29 & 35 & 54 & 0 & $6 / 8$ \\
\hline
\end{tabular}

Tabela 4. Notas de toxicidade do sulfentrazone nas plântulas de sorgo, para as classes de solo submetidas a índices pluviométricos crescentes (segundo a escala de notas da EWRC, 1964). Jaboticabal, SP, 1999/2000. (Média de 3 repetições).

\begin{tabular}{rcccccc}
\hline \multirow{2}{*}{$\begin{array}{c}\text { Prof. } \\
(\mathbf{c m})\end{array}$} & \multicolumn{6}{c}{ CLASSE DE } \\
\cline { 2 - 7 } & \multicolumn{4}{c}{ LVA } & \multicolumn{4}{c}{ LVdf } \\
\cline { 2 - 7 } & $\mathbf{3 0}$ & $\mathbf{6 0}$ & $\mathbf{9 0}$ & $\mathbf{3 0}$ & $\mathbf{6 0}$ & $\mathbf{9 0}$ \\
\hline $\mathbf{0 -} \mathbf{2 , 5}$ & 6 & 6 & 6 & 8 & 7 & 8 \\
$\mathbf{2 , 5 -} \mathbf{7 , 5}$ & 5 & 5 & 6 & 4 & 5 & 7 \\
$\mathbf{7 , 5 - 1 2 , 5}$ & 4 & 4 & 5 & 3 & 3 & 6 \\
$\mathbf{1 2 , 5 - 1 7 , 5}$ & 3 & 4 & 4 & 1 & 2 & 3 \\
$\mathbf{1 7 , 5 - 2 2 , 5}$ & 3 & 3 & 4 & 1 & 1 & 2 \\
$\mathbf{2 2 , 5 - 3 0 , 0}$ & 3 & 3 & 3 & 1 & 1 & 2 \\
\hline
\end{tabular}


Tabela 5. Efeito do sulfentrazone no Latossolo Vermelho distroférrico (LVdf), sob diferentes precipitações, sobre a altura $(\mathrm{cm})$, sobrevivência (\%) e biomassa seca $(\mathrm{g})$ do sorgo nas diferentes profundidades (média de 3 repetições). Jaboticabal/SP, 1999/2000.

\begin{tabular}{|c|c|c|c|c|}
\hline \multicolumn{5}{|c|}{ HERBICIDA X PRECIPITAÇÃO (HP) } \\
\hline TRATAMENTO & $\begin{array}{l}\text { PRECIP. } \\
\quad(\mathrm{mm})\end{array}$ & $\begin{array}{l}\text { ALTURA } \\
(\mathrm{cm})\end{array}$ & $\begin{array}{c}\text { SOBREV. } \\
(\%)\end{array}$ & $\begin{array}{c}\text { BIOMASSA } \\
(\mathrm{g})\end{array}$ \\
\hline \multirow{3}{*}{ SULFENTRAZONE } & 30 & $2,63 \mathrm{~A}^{1}$ & $70,02 \mathrm{~A}$ & $0,0244 \mathrm{~A}$ \\
\hline & 60 & $2,69 \mathrm{~A}$ & $76,29 \mathrm{~A}$ & $0,0302 \mathrm{~A}$ \\
\hline & 90 & $2,31 \mathrm{~A}$ & $77,86 \mathrm{~A}$ & $0,0255 \mathrm{~A}$ \\
\hline \multirow{10}{*}{ TESTEMUNHA } & 30 & $2,77 \mathrm{~A}$ & $76,52 \mathrm{~A}$ & $0,0239 \mathrm{~A}$ \\
\hline & 60 & $2,99 \mathrm{~A}$ & $76,97 \mathrm{~A}$ & $0,0318 \mathrm{~A}$ \\
\hline & 90 & $2,46 \mathrm{~A}$ & $79,88 \mathrm{~A}$ & $0,0266 \mathrm{~A}$ \\
\hline & ROF. $(\mathrm{cm})$ & \multicolumn{3}{|c|}{ PROFUNDIDADE $(\mathbf{P})$} \\
\hline & 2,5 & $1,55 \mathrm{D}$ & $62,11 \mathrm{~B}$ & $0,0154 \mathrm{D}$ \\
\hline & 7,5 & $2,09 \mathrm{C}$ & $75,16 \mathrm{~A}$ & $0,0211 \mathrm{C}$ \\
\hline & 12,5 & $2,78 \mathrm{~B}$ & $80,01 \mathrm{~A}$ & $0,0276 \mathrm{~B}$ \\
\hline & 17,5 & $3,08 \mathrm{AB}$ & $81,91 \mathrm{~A}$ & $0,0315 \mathrm{~A}$ \\
\hline & 22,5 & $3,13 \mathrm{AB}$ & $80,38 \mathrm{~A}$ & $0,0322 \mathrm{~A}$ \\
\hline & 30,0 & $3,22 \mathrm{~A}$ & $77,98 \mathrm{~A}$ & $0,0347 \mathrm{~A}$ \\
\hline $\mathrm{F}_{\mathrm{HP}}$ & & $1,44 \mathrm{NS}$ & $0,89 \mathrm{NS}$ & $2,72 \mathrm{NS}$ \\
\hline $\mathrm{F}_{\mathrm{P}}$ & & $61,84 * *$ & $10,38 * *$ & $75,42 * *$ \\
\hline HP x P & & $3,42 * *$ & $2,45 * *$ & $3,09 * *$ \\
\hline $\mathrm{CV}_{\mathrm{HP}}(\%)$ & & 32,16 & 19,53 & 30,59 \\
\hline $\mathrm{CV}_{\mathrm{P}}(\%)$ & & 13,81 & 12,63 & 13,38 \\
\hline
\end{tabular}

1: Médias seguidas de mesma letra não diferem significativamente entre si, pelo teste de Tukey ao nível de $5 \%$ de probabilidade. $* *$ e *: Significativo a 1 e $5 \%$ de probabilidade pelo teste F, respectivamente; NS: Não significativo pelo teste F. Precip. = precipitação, sobrev. = sobrevivência, prof. $=$ profundidade.

Tabela 6. Altura das plantas de sorgo $(\mathrm{cm})$, no Latossolo Vermelho distroférrico (LVdf), obtida no desdobramento da interação entre as diferentes profundidades e os tratamentos com e sem aplicação do sulfentrazone sob as diferentes precipitações (média de 3 repetições).

\begin{tabular}{rllllll}
\hline PROF & \multicolumn{3}{c}{ SULFENTRAZONE } & \multicolumn{3}{c}{ TESTEMUNHA } \\
\cline { 2 - 6 }$(\mathbf{c m})$ & \multicolumn{1}{c}{$\mathbf{3 0}$} & \multicolumn{1}{c}{$\mathbf{6 0}$} & \multicolumn{1}{c}{$\mathbf{9 0}$} & \multicolumn{1}{c}{$\mathbf{3 0}$} & \multicolumn{1}{c}{$\mathbf{6 0}$} & \multicolumn{1}{c}{$\mathbf{9 0}$} \\
\hline $\mathbf{2 , 5}$ & $0,72 \mathrm{Cb}^{1}$ & $1,46 \mathrm{Cab}$ & $1,12 \mathrm{Bab}$ & $1,96 \mathrm{Ca}$ & $2,21 \mathrm{Ba}$ & $1,81 \mathrm{Bab}$ \\
$\mathbf{7 , 5}$ & $1,53 \mathrm{Cbc}$ & $2,27 \mathrm{BCabc}$ & $1,13 \mathrm{Bc}$ & $2,35 \mathrm{BCab}$ & $2,78 \mathrm{ABa}$ & $2,49 \mathrm{ABab}$ \\
$\mathbf{1 2 , 5}$ & $2,87 \mathrm{Ba}$ & $2,85 \mathrm{ABa}$ & $2,52 \mathrm{Aa}$ & $2,71 \mathrm{ABCa}$ & $3,07 \mathrm{ABa}$ & $2,66 \mathrm{Aba}$ \\
$\mathbf{1 7 , 5}$ & $3,33 \mathrm{ABa}$ & $3,03 \mathrm{ABa}$ & $3,08 \mathrm{Aa}$ & $3,20 \mathrm{ABa}$ & $3,23 \mathrm{Aa}$ & $2,63 \mathrm{Aba}$ \\
$\mathbf{2 2 , 5}$ & $3,52 \mathrm{ABa}$ & $3,23 \mathrm{Aa}$ & $2,99 \mathrm{Aa}$ & $2,95 \mathrm{ABa}$ & $3,35 \mathrm{Aa}$ & $2,73 \mathrm{Aa}$ \\
$\mathbf{3 0 , 0}$ & $3,79 \mathrm{Aa}$ & $3,32 \mathrm{Aab}$ & $3,01 \mathrm{Aab}$ & $3,43 \mathrm{Aab}$ & $3,33 \mathrm{Aab}$ & $2,41 \mathrm{ABb}$ \\
\hline
\end{tabular}

1: Médias seguidas de mesma letra não diferem significativamente entre si, pelo teste de Tukey ao nível de $5 \%$ de probabilidade. Prof. $(\mathrm{cm})$ : diferentes profundidades. Letras maiúsculas são no sentido da coluna e comparam os efeitos das diferentes profundidades. Letras minúsculas são no sentido da linha e comparam os efeitos das precipitações sem aplicação e com aplicação do sulfentrazone. 
Tabela 7. Sobrevivência das plantas de sorgo (\%), no Latossolo Vermelho distroférrico (LVdf), obtida no desdobramento da interação entre as diferentes profundidades e os tratamentos com e sem aplicação do sulfentrazone sob as diferentes precipitações (média de 3 repetições).

\begin{tabular}{|c|c|c|c|c|c|c|}
\hline \multirow{2}{*}{$\begin{array}{c}\text { PROF } \\
(\mathbf{c m})\end{array}$} & \multicolumn{3}{|c|}{ SULFENTRAZONE } & \multicolumn{3}{|c|}{ TESTEMUNHA } \\
\hline & 30 & 60 & 90 & 30 & 60 & 90 \\
\hline 2,5 & $41,16 \mathrm{Bb}^{1}$ & $62,66 \mathrm{Bab}$ & $57,65 \mathrm{Bab}$ & $59,67 \mathrm{Bab}$ & $78,36 \mathrm{Aa}$ & $72,55 \mathrm{Aa}$ \\
\hline 7,5 & 66,96 Аa & $78,36 \mathrm{ABa}$ & $84,18 \mathrm{Aa}$ & $73,32 \mathrm{ABa}$ & $69,75 \mathrm{Aa}$ & $78,36 \mathrm{Aa}$ \\
\hline 12,5 & $73,32 \mathrm{Aa}$ & $66,96 \mathrm{ABa}$ & $90,00 \mathrm{Aa}$ & $84,18 \mathrm{Aa}$ & $75,57 \mathrm{Aa}$ & $90,00 \mathrm{Aa}$ \\
\hline 17,5 & 78,36 Аa & $84,18 \mathrm{ABa}$ & 75,57 ABa & 79,14 ABa & 84,18 Аа & $90,00 \mathrm{Aa}$ \\
\hline 22,5 & $75,67 \mathrm{Aa}$ & $90,00 \mathrm{Aa}$ & 75,57 ABa & $90,00 \mathrm{Aa}$ & $84,18 \mathrm{Aa}$ & $66,96 \mathrm{Aa}$ \\
\hline 30,0 & $84,18 \mathrm{Aa}$ & $75,57 \mathrm{ABa}$ & $84,18 \mathrm{Aa}$ & $72,78 \mathrm{ABa}$ & $69,75 \mathrm{Aa}$ & $81,39 \mathrm{Aa}$ \\
\hline
\end{tabular}

1: Médias seguidas de mesma letra não diferem significativamente entre si, pelo teste de Tukey ao nível de $5 \%$ de probabilidade. Prof. $(\mathrm{cm})$ : diferentes profundidades. Letras maiúsculas são no sentido da coluna e comparam os efeitos das diferentes profundidades. Letras minúsculas são no sentido da linha e comparam os efeitos das precipitações sem aplicação e com aplicação do sulfentrazone.

Tabela 8. Biomassa da parte aérea das plantas de sorgo (g), no Latossolo Vermelho distroférrico (LVdf), obtido no desdobramento da interação entre as diferentes profundidades e os tratamentos com e sem aplicação do sulfentrazone sob as diferentes precipitações (média de 3 repetições).

\begin{tabular}{|c|c|c|c|c|c|c|}
\hline \multirow{2}{*}{$\begin{array}{c}\text { PROF } \\
(\mathrm{cm})\end{array}$} & \multicolumn{3}{|c|}{ SULFENTRAZONE } & \multicolumn{3}{|c|}{ TESTEMUNHA } \\
\hline & 30 & 60 & 90 & 30 & 60 & 90 \\
\hline 2,5 & $0,0087 \mathrm{Cb}^{1}$ & $0,0143 \mathrm{Dab}$ & $0,0130 \mathrm{Cab}$ & $0,0167 \mathrm{Cab}$ & $0,0210 \mathrm{Ca}$ & 0,0190 Bab \\
\hline 7,5 & $0,0153 \mathrm{Cbc}$ & $0,0243 \mathrm{Cab}$ & $0,0123 \mathrm{Cc}$ & 0,0207 BCabc & $0,0277 \mathrm{BCa}$ & $0,0263 \mathrm{ABab}$ \\
\hline 12,5 & $0,0260 \mathrm{Ba}$ & $0,0303 \mathrm{BCa}$ & $0,0263 \mathrm{Ba}$ & $0,0227 \mathrm{BCa}$ & $0,0317 \mathrm{ABa}$ & $0,0287 \mathrm{Aa}$ \\
\hline 17,5 & $0,0307 \mathrm{ABa}$ & $0,0330 \mathrm{ABCa}$ & $0,0353 \mathrm{Aa}$ & $0,0270 \mathrm{ABa}$ & $0,0347 \mathrm{ABa}$ & $0,0283 \mathrm{Aa}$ \\
\hline 22,5 & $0,0307 \mathrm{ABab}$ & $0,0387 \mathrm{ABa}$ & $0,0330 \mathrm{ABab}$ & $0,0247 \mathrm{ABCb}$ & $0,0360 \mathrm{ABab}$ & $0,0300 \mathrm{Aab}$ \\
\hline 30,0 & $0,0353 \mathrm{Aab}$ & $0,0407 \mathrm{Aa}$ & $0,0330 \mathrm{ABab}$ & $0,0320 \mathrm{Aab}$ & $0,0400 \mathrm{Aa}$ & $0,0273 \mathrm{ABb}$ \\
\hline
\end{tabular}

1: Médias seguidas de mesma letra não diferem significativamente entre si, pelo teste de Tukey ao nível de $5 \%$ de probabilidade. Prof. $(\mathrm{cm})$ : diferentes profundidades. Letras maiúsculas são no sentido da coluna e comparam os efeitos das diferentes profundidades. Letras minúsculas são no sentido da linha e comparam os efeitos das precipitações sem aplicação e com aplicação do sulfentrazone. 
Tabela 9. Efeito do sulfentrazone no Latossolo Vermelho - Amarelo (LVA), sob diferentes precipitações, sobre a altura $(\mathrm{cm})$, sobrevivência (\%) e biomassa $(\mathrm{g})$ do sorgo nas diferentes profundidades (média de 3 repetições). Jaboticabal/SP, 1999/2000.

\begin{tabular}{|c|c|c|c|c|}
\hline \multicolumn{5}{|c|}{ HERBICIDA X PRECIPITAÇÃO (HP) } \\
\hline TRATAMENTO & $\begin{array}{c}\text { PRECIP. } \\
(\mathrm{mm})\end{array}$ & $\begin{array}{l}\text { ALTURA } \\
(\mathrm{cm})\end{array}$ & $\begin{array}{c}\text { SOBREV. } \\
(\%)\end{array}$ & $\begin{array}{c}\text { BIOMASSA } \\
(\mathrm{g})\end{array}$ \\
\hline \multirow{3}{*}{ SULFENTRAZONE } & 30 & $2,33 \mathrm{AB}^{1}$ & $75,84 \mathrm{AB}$ & $0,0204 \mathrm{ABC}$ \\
\hline & 60 & $1,90 \mathrm{AB}$ & $69,72 \mathrm{AB}$ & $0,0214 \mathrm{ABC}$ \\
\hline & 90 & $1,68 \mathrm{~B}$ & $76,85 \mathrm{AB}$ & $0,0196 \mathrm{BC}$ \\
\hline \multirow{10}{*}{ TESTEMUNHA } & 30 & $1,90 \mathrm{AB}$ & $62,66 \mathrm{~B}$ & $0,0176 \mathrm{C}$ \\
\hline & 60 & $2,47 \mathrm{~A}$ & $82,28 \mathrm{~A}$ & $0,0262 \mathrm{~A}$ \\
\hline & 90 & $2,26 \mathrm{AB}$ & $78,66 \mathrm{AB}$ & $0,0249 \mathrm{AB}$ \\
\hline & PROF. (cm) & \multicolumn{3}{|c|}{ PROFUNDIDADE $(\mathbf{P})$} \\
\hline & 2,5 & $1,80 \mathrm{C}$ & $67,17 \mathrm{~B}$ & $0,0196 \mathrm{CD}$ \\
\hline & 7,5 & $1,88 \mathrm{C}$ & $82,28 \mathrm{~A}$ & $0,0192 \mathrm{D}$ \\
\hline & 12,5 & $1,99 \mathrm{BC}$ & $71,21 \mathrm{AB}$ & $0,0206 \mathrm{BCD}$ \\
\hline & 17,5 & $2,33 \mathrm{~A}$ & $72,43 \mathrm{AB}$ & $0,0233 \mathrm{AB}$ \\
\hline & 22,5 & $2,45 \mathrm{~A}$ & $78,23 \mathrm{AB}$ & $0,0251 \mathrm{~A}$ \\
\hline & 30,0 & $2,09 \mathrm{~B}$ & $74,70 \mathrm{AB}$ & $0,0224 \mathrm{ABC}$ \\
\hline $\mathrm{F}_{\mathrm{HP}}$ & & $5,13 *$ & $4,63 *$ & $7,44 * *$ \\
\hline $\mathrm{F}_{\mathrm{P}}$ & & $28,19 * *$ & $3,78 * *$ & $10,26 * *$ \\
\hline $\mathrm{HP} \times \mathrm{P}$ & & $1,55 \mathrm{NS}$ & $0,74 \mathrm{NS}$ & $1,14 \mathrm{NS}$ \\
\hline $\mathrm{CV}_{\mathrm{HP}}(\%)$ & & 27,88 & 18,69 & 23,45 \\
\hline $\mathrm{CV}_{\mathrm{P}}(\%)$ & & 9,79 & 15,73 & 14,14 \\
\hline
\end{tabular}

1: Médias seguidas de mesma letra não diferem significativamente entre si, pelo teste de Tukey ao nível de $5 \%$ de probabilidade. ${ }^{* *}$ e *: Significativo a 1 e $5 \%$ de probabilidade pelo teste F, respectivamente; NS: Não significativo pelo teste F. Precip. $=$ precipitação, sobrev. $=$ sobrevivência, prof. $=$ profundidade . 